\title{
How domestication alters fish phenotypes
}

2

Milla S., Pasquet A., Mohajer L., Fontaine P.

University of Lorraine, INRA, UR AFPA, F-54000 Nancy

\section{Corresponding author:}

8 Dr. Sylvain MILLA, Sylvain.Milla@univ-lorraine.fr; Tel. 00(33) 372745199

9 Faculté des Sciences et Technologies, bâtiment 2ème cycle, entrée 1B

10 Boulevard des Aiguillettes

1154506 Vandoeuvre-Lés-Nancy Cedex, France

12

Domestication can be defined as the adaptation of an animal to the human environment and

its constraints. Accumulating evidence strongly indicates that domestication plays essential roles in modulating the phenotypes of teleosts, despite the scattered information. Animal husbandry and molecular, physiological, and behavioural studies have identified a high degree and complexity of biological changes induced by domestication. These phenotypic modifications during domestication vary greatly amongst species and physiological function (e.g. growth, reproduction, response to stress, and immunity), probably due to a variety of intrinsic and extrinsic factors that can interfere with phenotypic changes. Indeed, much information about domestication is lacking, which impedes the generalisation of our understanding of the effects of domestication. This review gathers and clarifies the available information about the main effects of fish domestication. We use a broad physiological approach for understanding these biological consequences, from the genesis of domestication (e.g. netting from the wild) to the ultimate step (controlled artificial selection). We also suggest ways to predict the effects of domestication and to better understand the sources of the biological changes. 
Keywords: domestication; fish; physiology; reproduction; stress; immunity

\section{Introduction}

The most recent FAO (Food and Agriculture Organization) reports found that captures from fisheries have been quite stable since the late 1980s, but aquaculture is still the key driver of the growing supply of fish for human consumption. The future of aquaculture will require the continuation of some economic models of sector development. Amongst these models, fish diversification is one way expected to support the growing aquacultural production, because this way of promoting aquaculture has many advantages at the social, ecological, and economic levels (Wellenreuther et al. 2019)(Fontaine et al. 2009). Diversification, however, requires the domestication of new species, which often faces serious bottlenecks linked to the lack of control of the life cycle. This strategy is thus not a priori the easiest, because the domestication of a new species is a long, difficult, and expensive process and is often conducted empirically (Teletchea and Fontaine 2014). Understanding and conceptualising the effects of domestication on fish phenotypes is of paramount importance for limiting failures of domestication.

Domestication is defined as the process by which a population of animals becomes adapted to humans and captive environments by one or more combinations of genetic modifications throughout generations and developmental events induced by the environment, recurring in each generation (Price 1999). Domestication at the individual or population level starts with the transfer of animals from the wild (F0 fish) to a captive environment where they are faced with a new living environment. Each history of domestication is unique, and the populations during domestication undergo a range of biological phenomena linked to human practices. These mechanisms contribute to genetic, genomic, and phenotypic changes of the animals. Some changes are not easily controlled by humans, such as inbreeding and genetic drift that 
depend on the numbers of broodstock used in each generation. Natural selection in captivity promotes the survival of animals that are best adapted to the rearing environment and eliminates those unable to reproduce (Mignon-Grasteau et al. 2005). Multiple adaptive failures are common in the early generations due to a lack of human control of the capacity of some specimens to reproduce (unsuitable timing and egg and larval quality) or even to survive in captivity. Humans, however, can relax natural selection in captivity, which consists in reducing the selection pressure for some traits (e.g. breeding season, fish size, and fish feeding). Finally, artificial selection is the process by which we voluntarily select broodstock for a given objective of production (Mignon-Grasteau et al. 2005). The objective may be uncontrolled if the traceability and conditions of artificial selection are not fully monitored or may be considered as controlled if the objective is part of a rigorous genetic breeding programme tracked over several generations. Both types of selection (natural and artificial) may affect allelic frequencies or lead to mutations at some major loci (e.g. promoters) that may also affect the emergence of phenotypes (Wittkopp and Kalay 2011). These adaptive mechanisms are also linked with alterations of gene expression that are likely to modify fish phenotypes (Christie et al. 2016).

A theory of syndrome domestication has recently been proposed that accounts for such phenotypic changes in mammals (Wilkins et al. 2014). The theory suggests that some morphological, behavioural, and physiological alterations in domesticated animals may be due to mild deficits of neural-crest cells during embryonic development. Such deficiencies are proposed to be the sources of the modified morphological, behavioural, and physiological traits. Fish domestication, however, displays some specific characteristics compared to mammals, independent of these phenotypic changes. First, fish production benefits from a range of specific rearing systems, from production in ponds to intensive production in recirculated aquacultural systems (RASs), each offering one specific trajectory of 
domestication (Fontaine \& Teletchea 2019). Second, each trajectory offers the opportunity of many paths of domestication, which can be defined as the set of husbandry practices applied by the farmer (e.g. type of diets, fish density, temperature/lighting conditions) and the set of unpredictable events (climate, stressors, disease). This multiplicity of domestication paths is made possible by biological diversity, which is much higher in fish than mammals. Third, domestication is generally recent, with most captive species domesticated in recent decades (Teletchea and Fontaine 2014) and with numerous and rapid phenotypic changes even in the early generations. Fourth, bilateral flows are high between wild and captive individuals that could interfere with the progress of domestication, e.g. by the transfer of pathogens or the modification of genetic variability (Lorenzen et al. 2012). These peculiarities confer to fish the status of a relevant model for identifying the consequences of vertebrate domestication. Growing evidence suggests that domestication induces large changes at the ecological, behavioural, anatomical, and physiological levels, but some of these changes are controversial, depending on the species and especially on the biological function investigated. The aim of this review is first to clarify these equivocal effects along the successive steps of domestication that can strongly modify fish phenotypes or population structure and then to discuss how to develop new research strategies for exploring these effects in the future. We propose to break down the process of domestication into five main steps that greatly influence fish phenotype (Figure 1).

\section{1-Capture, transport (step 1), and acclimation (step 2)}

Transfer from the wild to rearing conditions is the first crucial step in the domestication of fish (Figure 1). Several manipulations (e.g. fishing, handling, and transport) occur during this stage that constitute mechanical, physicochemical, social, and sensory stressors likely to 
disrupt many biological functions. The transport of fish is accompanied by severe modifications to water quality (e.g. acidification and increased concentrations of ammonia and carbon dioxide) and potentially mortality (Sampaio and Freire 2016). Strong stressors such as netting, exposure to air, handling, and transport can greatly perturb endocrine function, marked by increased releases of catecholamines and corticosteroids. These hormonal inductions are accompanied by physiological alterations such as demineralisation, immunological and haematological alterations, increased glycemia, and depressed production of sex steroids (Wedemeyer and Wydoski 2008; Cho et al. 2009; Nikoo and Falahatkar 2012), leading to well-known effects on fish biological functions. Most of these parameters return to resting levels in the surviving fish within $48-72 \mathrm{~h}$ after capture, indicating that the species can regain their physiological homeostasis within a relatively short time if the duration and intensity of the stresses linked to capture are mild. This period of allostatic load (physiological adjustment) that can be considered as the second step of domestication (Figure 1) corresponds to the period of acclimation (Segner et al. 2012) of the wild fish to the captive environment, where the fish are exposed to a multiplicity of cultured conditions (Lorenzen et al. 2012).

The success of acclimation is multifactorial in that it implies a complex response of the organism characterised by a way of life that differs greatly between the wild environmental conditions and those provided by the cultured system. Successful acclimation requires that all these environmental features of the rearing system (e.g. temperature, salinity, and ammonia concentration) be within the range of those compatible with the biological requirements of the species and the population (Ibarra-Zatarain et al. 2016). The capacity to acclimate thus depends on the level of divergence between the two environments but also on the characteristics of transition from the wild to captivity (e.g. acute vs progressive acclimation) and finally on the size and developmental stage of the fish caught in the wild (fertilised eggs 
vs juveniles; e.g. (Okpala et al. 2017)). This challenge experienced by fish newly introduced to captivity may induce non-inherited changes in behaviour. This adopted behaviour is also vital, because the way the fish feed, compete or interfere with congeners or even to avoid potential predators are determinants of their survival (Huntingford et al. 2012). For example, feeding with artificial diets in RASs markedly modifies nutritional behaviour, notably for piscivorous fish species.

Increased growth becomes apparent within the first few weeks or months following the transfer to husbandry in response to safe rearing conditions (Lorenzen et al. 2012) and in case of adequate behaviour to eat and survive. The expenditure of energy is probably lower under ad libitum feeding than in the wild, allowing the animal to optimise growth. Fish growth is a main zootechnical endpoint in aquaculture, so positive modulation of growth is a positive effect of domestication from the human point of view. Other biological functions, though, may be altered in wild fish acclimated to captive conditions.

\section{2-First reproduction in captivity (step 3)}

Obtaining the first generation of captive fish from wild fish is the third step of domestication (Figure 1). This step allows the production of fry that have never experienced the wild and involves the initial mechanisms of adaption to the rearing conditions. The stages of gametogenesis in wild broodstock acclimated in farms may nevertheless not be fully completed in the rearing conditions, and these wild fish do not always successfully respond to the hormonal stimulations used for inducing gonadal maturation (Hassin et al. 1997; Krejszeff et al. 2009). This failure in reproductive control is not due to changes in genetic characteristics but to multiple differences in environmental and social factors between wild and cultured fish that disrupt hormonal control at the level of the hypothalamus-pituitary- 
gonadal axis compared to the natural endocrine variations in the wild (Hassin et al. 1997).

158 Changes in external factors such as temperature and/or photoperiod are important for driving the progress of gonadogenesis in temperate fish species (Wang et al. 2010), and the failure to mimic these environmental cues in husbandry may be the cause of poor reproductive performance. The accurate control of photothermal programmes is thus assumed to help increase the control of the stages of gametogenesis in wild fish dedicated to the renewal of broodstock populations. Even if acclimation is successful, chemical and physical stressors in captivity are additional external factors that may further disrupt the progress of the reproductive cycle in these F0 fish (Cleary et al. 2000). These stressors have well-known effects on reproductive success (Milla et al. 2009), but other sources of failure in mating programmes may be applied to broodstocks caught in nature. Indeed, reproductive defaults in wild broodstock are not necessarily due to defects in these environmental features but may also be due to the nutritional and energetic conditions provided by the systems of husbandry, as observed in wild cod (Gadus morhua) (Lambert et al. 2000). These eclectic causes of reproductive dysfunction indicate the importance of fully investigating and checking the suitability of the rearing conditions to the long-term survival of the wild fish. Step 3 of domestication, the success of obtaining a first generation in captivity (F1 fish), may remain illusory if these requirements are not fulfilled.

\section{3-Adaptation and phenotypic changes (step 4)}

After the first successful reproduction, the next generations in captivity further strengthen the progressive adaptation that leads to large phenotypic changes driven by natural selection and/or by uncontrolled artificial selection by fish producers. These changes can be considered as the fourth step of domestication (Figure 1). 


\section{3-1-Growth, nutrition and flesh quality}

184

185

Controlled artificial selection for growth has greatly accelerated weight gains in fish,

especially salmonid fishes. Higher growth rates accompanied by higher conditions factors, however, have also been observed in domesticated salmonids where artificial selection has been poorly controlled (Table 1; Glover et al. 2009; Hedenskog, Petersson, and Järvi 2002; Solberg et al. 2013; Tymchuk, Beckman, and Devlin 2009; Tymchuk and Devlin 2005).

Domestication without controlled artificial selection, though, is not necessarily linked to increased growth (Brummett et al. 2004; Vandeputte et al. 2009). The physiological mechanisms underlying this divergence between wild and domesticated fish, intentionally or unintentionally selected, are poorly known. Differential levels of GH (Growth Hormone) or IGF-1 (Insulin Growth Factor-1) may be physiological indicators of this salmonid response (Fleming et al. 2002; Tymchuk et al. 2009). Contrasting nutritional behaviour may also account for this response. Foraging activity is also modified during domestication, even though it has only been demonstrated in a small range of fish species (Huntingford et al. 2012). Some species that have been more intensely domesticated, under controlled artificial selection for growth or not, stay near the water surface rather near the bottom of the water column (Reinhardt et al. 2001; Robison and Rowland 2005), which in turn improves their feeding efficiency (Thodesen et al. 1999; Sánchez et al. 2012). Changes in social behaviour, 202 e.g. shoaling, would be an additional behavioural cause of the higher growth in domesticated 203 fish (Wright et al. 2006; Pasquet et al. 2019), potentially due to a higher homogeneity of age and size in domesticated fish (Ruzzante and Doyle 1991, 1993). This change in the structure of the social group may induce modifications of aggressiveness and hierarchy between 
individuals (Swain and Riddell 1990; Ruzzante and Doyle 1993; Lucas et al. 2004) that would alter feeding behaviour and may improve growth.

Differential diets and levels of growth are apparently accompanied by differential flesh quality between wild and farmed fish, as demonstrated by Eurasian perch (Perca fluviatilis) (Mairesse et al. 2007), salmon (Salmo salar) (Johnston et al. 2006), sea bass (Dicentrarchus labrax), and sea bream (Sparus aurata) (Grigorakis 2007). These differences are marked by higher lipid content and fillet firmness in domesticated fish, potentially due to higher collagen content (Johnston et al. 2006). Cultured sea bass also contain more fat than their wild counterparts (Fuentes et al. 2010), and even the lipid composition of muscle differs, with a higher content of monounsaturated fatty acids and lower contents of saturated and polyunsaturated fatty acids, except n-6 polyunsaturated fatty acids that are more abundant in farmed sea bass (Fuentes et al. 2010; Lenas et al. 2012). Finally, some amino acids that characterise the flavour of fish, such as glutamic acid, aspartic acid, alanine, and glycine, are more abundant in cultured sea bass. These differences, notably those in the lipid profile, however, may not be common in all domesticated species (Samy Yehya El-Zaeem 2012). The type of breeding system may also influence this divergence in the lipid profile between wild and domesticated fish (Mairesse et al. 2006).

\section{3-2-Reproductive function}

Some fish in each of the next generations (F1-FX) are used as broodstock to produce new offspring in captivity, which progressively leads to the fourth step of domestication, regardless of the quality of these successive reproductive periods, provided that the fingerlings are viable and able to become future broodstock in captive conditions. The possibility of mating requires the attainment of puberty, which is defined as the 
developmental period during which an individual first becomes capable of reproducing sexually. Precocious puberty is a major problem in a wide range of farmed fishes, because puberty adversely affects growth. For example, male sea bass under natural conditions in the Mediterranean Sea reach sexual maturity at the age of two years. Early puberty under intensive culturing conditions, however, affects $20-30 \%$ of one-year-old males in the population (Felip et al. 2008). The increased growth in domesticated fish is probably one of the major causes of early puberty in farmed species (Taranger et al. 2010). The quality and timing of the stages of gametogenesis are very important for further spawning, fertilisation, and embryonic development. Many reproductive traits in captivity are affected by natural selection and/or uncontrolled artificial selection during domestication. Reproductive tactics such as spawning frequency may be modified (Krejszeff et al. 2010), accompanied by changes to the reproductive capacity of the progenitors, with modifications of their physiological status (Dannewitz et al., 2004; Krejszeff et al., 2009).

These effects of domestication on fish reproduction, though, are quite controversial, which questions the zootechnical assets to go deeper in the domestication by keeping the domesticated broodstock to obtain the next offspring generations, rather than renewing the broodstock at each generation by catching wild fish. Studies have reported a higher reproductive capacity in domesticated than wild fish, e.g. cyprinid fishes whose ovulatory response to hormonal treatments is higher in cultured fish (Krejszeff et al. 2009, 2010). Reproductive capacity (spawning success and fecundity) in Nile tilapia (Oreochromis niloticus) was higher in the most domesticated fish strain than in a strain collected from the wild (Osure and Phelps 2006). Other recent studies did not find clear differences in the reproductive features between wild and domesticated fish. Gonadogenesis in the Eurasian perch and pikeperch (Sander lucioperca), was more precocious in populations that were more domesticated (Khendek et al. 2017, 2018; De Almeida et al. 2019), but reproductive 
performance was generally better for the wild fish (Křšst'an et al. 2012; Khendek et al. 2017). As another example, reproductive parameters and the biological quality of eggs in a farmed population were compared to those of the original wild population in brown trout (Salmo trutta). Except for egg diameter, the reproductive traits were similar in both populations (Randak et al. 2006). In contrast, most published data have indicated degraded reproductive performance of captive fish relative to less domesticated populations. Several features are common in captive fish, notably slower or blocked gametogenesis, lower levels of sex hormones, smaller and lighter eggs, and lower reproductive success (Table 2). Modifications of reproductive behaviour may also be a source of decreases in reproductive success. For example, the hierarchical position of captive male coho salmon (Oncorhynchus kisutch) during mating is lower relative to the wild broodstock, decreasing the reproductive success of wild males by 50\% (Neff et al. 2015). Drawing bold conclusions about the effects of domestication on reproductive capacity may thus be premature.

\section{Identifying the main causes of this divergence of reproductive success between wild and} cultured strains is important. Published causes are rare, and tentative explanations can be quite speculative. One hypothesis is the deviation of fatty acid composition, storage, and metabolism, as reported for tabarana (Salminus hilarii) (Araújo et al. 2012), because the composition of fatty acids, notably unsaturated fatty acids, is a major determinant of the quality of fish eggs (Sorbera et al. 2001). The modification of genetic features during domestication is another putative source of differences between wild and domesticated fish. Genetic variability may decrease generation after generation, illustrated by decreased heterozygosity and allelic diversity (Sánchez et al. 2012). A decrease in this genetic diversity is often associated with changes in phenotypic characteristics (David 1999). Significant correlations between markers of heterozygosity and biological reproductive traits are good 
indications that a decrease in genetic diversity can be linked to modifications in reproductive success (Lieutenant-Gosselin and Bernatchez 2006; Kalbe et al. 2009). Relying on the genetic diversity based on these data to identify the direction of the effects of domestication, however, is quite difficult, because the correlations between these genetic markers and the level of phenotypic reproductive performance are not clearly positive or negative. This divergence of reproductive success may also be due to putative differences in reproductive behaviour, but very few data support this premise. Human bias in the reproductive sequence of reared fish populations relative to the sequence in the wild is the most obvious cause, notably by removing the choice of sexual partners. Conversely, the reproductive behaviour of domesticated fish released in the wild causes relevant changes in some characteristics of the reproductive strategy (Pasquet 2019), which may also account for the modifications to mating performance during domestication.

\section{3-3-Immunity and resistance to pathogens}

Improvement of fish immunity is of primary importance to resist pathogenic invasion and to avoid disease proliferation in fish farms. Independently of artificial breeding programmes, taking into account the advancement of the domestication process to optimise the resistance to pathogens is not voluntary applied so far as there is little available information from the literature. Some indications, however, suggest that this strategy may be relevant to strengthening the immune potential of captive fish. One generation of domestication of the rainbow trout (Oncorhynchus mykiss), altered the expression of hundreds of genes, with gene ontology indicating that immunity over-represented some of the main gene classes in that list (Christie et al. 2016), as for the Australasian Snapper (Chrysophrys auratus) (Wellenreuther et al. 2019). The differential serum proteome between two generations of the Eurasian perch, displayed mainly immunological proteins, also suggesting that immunity is a primary target in 
tissues or cellular fluids affected by domestication (Douxfils, Mandiki, et al. 2011; Douxfils, Mathieu, et al. 2011; Chen et al. 2017). The rationale to understand this differential expression of genes associated with immunology may depend on the environmental conditions of the domesticated fish, reared under crowded conditions where the crosscontamination of individuals with pathogens is favoured. Domestication would thus modify the fish transcriptome and proteome to allow adaptation to high densities in captivity.

Changes in mRNA or protein levels, however, are not typically correlated with the level of protein activity (Greenbaum et al. 2003), because post-transcriptional and -translational modifications may ultimately affect the functionality of proteins. Studies of differential gene expression at transcript and protein levels thus cannot substitute for detailed functional analyses of candidate genes. These molecular studies generally do not validate a modified change in the immune response to pathogenic invasion. Whether or not domestication is linked to either immunostimulatory or immunosuppressive effects and in turn to conclusions about the usefulness of appealing to long-term adapted captive fish to further boost fish immunity is difficult to distinguish. To clarify, the comparative effect of bacterial challenges to fish mortality and immunity is a convenient tool for evaluating the positive benefits of domestication. Wild and domesticated strains of Atlantic salmon respond similarly to Aeromonas salmonicida (Glover et al. 2009), but levels of immunological parameters were higher in F4 than F1 perch after infection with Aeromonas hydrophila (Douxfils, Mandiki, et al. 2011). Definitively concluding that the effects of domestication improve fish immunity is thus currently too premature, but the first molecular results of the effect of domestication on cellular signalling pathways are very promising.

\section{3-4-Response to stress}


In addition to the immune response after pathogenic invasion, the ability of fish to cope with aquacultural stressors is of paramount importance for the survival, growth, and reproductive capacity of the fish. Fish possess anatomical, physiological, and behavioural strategies to respond to stressors in aquacultural conditions. They display evidence of escape responses associated with long-term memories of frightening events in captivity (Yue et al. 2004). Specialised brain structures implied in the response to suffering and active nociceptors are indications of a neurophysiological response to painful experiences (Sneddon et al. 2003). The impacts of stressors due to husbandry on the level of stress or pain hormones, such as catecholamines, corticosteroids, or opioids, indicate that domesticated fish are sensitive to these stressors (e.g. (Øverli et al. 2001)). Interestingly, these behavioural and physiological characteristics are affected by domestication.

The longer fish are domesticated, the lower their levels of stress hormones relative to wild fish after exposure to acute or chronic stressors (Awata et al., 2011; Douxfils et al., 2011a; Mazur and Iwama, 1993; Table 3). For example, wild trout have higher post-stress levels of plasma glucose and DOPAC/DA than domesticated fish after exposure to a novel environment or a predator (Lepage et al. 2000). These studies have unfortunately not linked the anatomical, behavioural, or physiological alterations to identify relationships between the progressive changes in the organs implied in the stress axis (brain, pituitary, and interrenal cells), the modifications of hormones associated with stress, and the behavioural consequences. Concluding whether this inhibition of the corticotropic axis is due to hypoplasia of interrenal cells, a decrease in corticotropic enzymes or cortisol receptivity, or even behavioural changes is thus difficult. How the effects of domestication on the attenuation of these physiological indicators of stress can benefit the animals is also not clear. At the behavioural level, domestication may reduce the responses to escape predation, as demonstrated in a wide range of teleost species. Indeed, wild fish react to predators more 
rapidly and intensively than domesticated fish, and this natural reaction attenuates over the first few generations of domestication (see (Pasquet 2019) for review). This effect of domestication is likely linked to physiological changes, where fish usually respond to stressors by altering physiological function in an attempt to reallocate energy for coping with stress (Schreck et al. 2001). The concept of coping style has emerged in recent decades, with personality and other new behavioural concepts such as "temperament" and "behavioural syndromes". This new field of research has established links between behavioural and physiological indicators: “Coping refers to the individual's behavioural and physiological efforts to manage (reduce, minimize, master, or tolerate) the internal and external demands of a situation that is appraised as stressful, and taxing or exceeding the individual's resources" (Koolhaas et al. 1999). Coping styles in several domesticated freshwater and marine species of aquacultural importance have attracted great interest (Castanheira et al. 2017), such as the common carp (Cyprinus carpio), Nile tilapia, Atlantic salmon, Atlantic halibut (Hippoglossus hippoglossus), rainbow trout, sea bass, Senegalese sole (Solea senegalensis), and gilthead sea bass. These coping styles are consistent over time, so they are reliable for assessing individual fluctuations in response to stress. Two groups of animals are identified based on their coping styles: proactive and reactive animals. Proactive animals have a bolder, more aggressive and less flexible behavioural response to stress, with a lower physiological HPA reactivity (lower cortisol level), and reactive animals have opposite behavioural and physiological responses (Vindas et al. 2017).

Some recent experiments have demonstrated that the physiological response of domesticated fish to stressors is linked to coping style. The use of thermal gradients affects physiological and behavioural traits in Nile tilapia described as personality, and the proactive individuals preferred the higher temperatures that could be directly linked with their metabolism (Cerqueira et al. 2016). Styles of coping with stress in juveniles and breeders have been 
characterised in Senegalese sole (Ibarra-Zatarain et al. 2016). Behavioural tests can differentiate between two groups of individuals: "fearfulness-reactive" and "activeexploration" individuals, which correspond to the defined proactive and reactive individuals with low and high levels of cortisol, respectively. Boldness, which is the propensity to take risks, is strongly linked to cortisol level in juvenile mulloway (Argyosomus japonicus) siblings (Raoult et al. 2012) after exposure to a stressor, with lower levels in bold individuals (proactive) in response to the stressor. Similar results have been reported for Senegalese sole (Silva et al. 2010), with proactive individuals having a shorter feeding latency (time to react to feed), longer duration of escape attempts from a net, and lower cortisol levels (before the stressful situation) than for reactive individuals, suggesting the existence of stress-coping styles in this species.

All these examples indicate that individual behavioural differences in a domesticated population in response to stressors are directly linked to the secretion of the stress hormone cortisol. The level of corticosteroids, however, is not the only indication of coping styles in fish. For example, domesticated fish approach a novel object more readily and take more risks, and these behavioural differences are often accompanied by physiological variations linked to cardiovascular activity (Pasquet 2019). These differences indicate that responses towards frightening stimuli are less intense in domesticated than wild fish and that these responses may be due to changes in physiological activity. A comparison between a wild-type and a domesticated strain of the fighting fish (Betta splendens), produced similar results, with the domesticated strain adopting a behavioural strategy of immobility during confinement, contrary to the wild fish (Verbeek et al. 2008). The domesticated individuals were predicted to exhibit a more proactive coping style characterised by a lower level of cortisol and a stronger sympathetic response (opercular beat rate) to non-social challenges (unfamiliar environment, spatial confinement). 
We should, however, be cautious in evaluating if the effects of domestication on the inhibition

407

408

409

410

411

412

413

414

415

416

417

418

419

420

421

422

423

424

425 of the corticotropic axis is always linked to behavioural changes. Some studies have reported changes in coping styles between wild and domesticated fish, but other studies prevent us from generalising this correlation between behavioural and physiological traits to all species and all stressors. For example, newly emerged fry of domesticated Atlantic salmon were tested for their behavioural responses to resume feeding after transfer to rearing in isolation. Bolder individuals adapted to the new situation more rapidly than shy individuals, and this difference remained after several months. Post-stress concentrations of cortisol, however, did not differ between the bold and shy individuals (Vaz-Serrano et al. 2011).

\section{4-Effect of the controlled artificial selection (step 5)}

Controlled artificial selection at the species level is part of the advanced stages of domestication (Teletchea and Fontaine 2014). Step 5 at the population and individual levels may also be considered as the ultimate degree of domestication (Figure 1) even if it can occur in parallel with stage 4, requiring that some former steps (at least steps 1-3) have been achieved. Step 5 is often used to optimise growth and relevant biological functions. One of the primary objectives of aquaculture is to produce the highest amount of piscine proteins while optimising food efficiency and flesh quality, so controlled artificial selection of growth has been the first goal of selection. Estimates of the heritability of traits associated with growth range from 0.10 to 0.60 (Priars and Smith 2010). This moderate to high heritability has been used to select for growth, which has increased weight or length relative to unselected fish (e.g. 
(Vandeputte et al. 2009)). Reproductive capacity is not a usual target of controlled artificial

432 selection in aquacultured fish, but markers of reproductive capacity are potentially relevant heritable traits that may be investigated to strengthen the reproductive performance of captive stocks (Trong et al. 2013a). Estimates of heritability, however, vary widely depending on the species and type of reproductive trait: puberty, fecundity, or traits associated with spawning (Trong et al. 2013a; b). The heritability of reproductive traits is generally similar to or slightly lower than the heritability of traits associated with growth (Friars and Smith 2010), but the little information available from the literature suggests that good progress may be expected by selecting for age at maturation or for gamete quality.

Controlled artificial selection of the immune response in the future could potentially improve the genetics of fish. Outbreaks of disease is an important bottleneck for the development of intensive aquaculture worldwide. The choice of selected lines with traits linked to the capacity to combat viral, bacterial, and parasitic diseases has been successful in a variety of species (Gjedrem 2012). A prerequisite is the availability of a sufficient proportion of highly heritable traits linked to immunity to target as an added protection against disease. Such heritability, however, is low to moderate (from 0.05 to 0.38 ) and is highly species-dependent, which renders this route of investigation unclear and requires selecting the best relevant traits (Mohanty et al. 2012; Evenhuis et al. 2015; Silva et al. 2019; Srisapoome et al. 2019). Identifying QTLs linked to immunological parameters, however, could be another way to implement such major traits in schemes of controlled artificial selection (Fraslin et al. 2018).

The selection of low-stress responders may be a good strategy to attenuate the impact of stress 452 on growth, reproduction, or immune defence. Divergent lines have been selected based on the 453 level of plasma cortisol following stress in rainbow trout (Pottinger et al. 1992). The 454 heritability of the response of cortisol to stress varies strongly amongst species: $0.27-0.50$ in rainbow trout, 0.60 in carp, but only 0.05 in Atlantic salmon and 0.08 in sea bass (Volckaert 
et al. 2012). Interspecific differences, the type of stressor applied, and other methodological biases may account for these discrepancies.

Controlled artificial selection is usually driven by a single biological function (growth, reproduction, or immunity), but the selection of strains with a higher growth potential may indirectly contribute to altering the reproductive capacity of the broodstock. For example, genetic correlations between growth and reproductive features in salmonids are associated with these biological functions (O'Malley et al. 2003; Tentelier et al. 2016). The controlled artificial selection for growth can decrease the proportion of mature male parrs (Harvey et al. 2018), and genetic interaction has been reported between body weight and early maturation of female in Nile tilapia, suggesting that selection for larger body weight may lead to early puberty in females (Longalong and Eknath 1995).

Also, such selection for body size in salmon decreased anti-predatory behaviour (Johnsson et al. 2001) and the strength of the hypothalamus-pituitary-interrenal (HPI) axis, as discussed earlier, implying that the effect of domestication on the attenuation of stress may be due to genetic interactions with growth. This implication is supported by negative genetic interactions of cortisol level with body weight and standard body length that have been calculated for confined sea bass (Volckaert et al. 2012), suggesting that targeting genetic selection for aspects of both growth and stress is possible, at least in sea bass.

Immunity may also be a consequence of controlled artificial selection. For example, a study of the gill transcriptome of $S$. salar found a set of differently expressed genes between wild and domesticated fish selected for growth. Eight of these genes had adaptative and innate immune functions, indicating that immunity was one of the biological functions altered by domestication under controlled artificial selection (Debes et al. 2012).

In contrast to these growth $\times$ reproduction, growth $\times$ stress and growth $\times$ immunity genetic interactions, the response to stress was not correlated with reproductive capacity in rainbow 
trout (Pottinger and Carrick 2000). If a genetic interaction is not generalisable to all species and all breeding programmes (Thoa et al. 2017), then controlled artificial selection for body size during domestication may inadvertently affect physiological traits and in turn induce unexpected consequences. The modification of fish behaviour during domestication that could also interfere with these other biological functions is another potential bias. In particular, the selection of some lineages of fish based on their potential for growth and development can influence other life traits, especially behavioural traits (Pasquet 2019). More generally, attention must be paid to the collateral effects of controlled artificial selection.

The aim of selection programmes is genetic progress and the preservation of genetic diversity. These programmes, however, can have many consequences on genetic diversity (Dupont-Nivet et al. 2006). Some programmes with high levels of inbreeding and in turn the alteration of genetic diversity can strongly decrease zootechnical performance linked to reproduction (Langen et al. 2017), resistance to pathogens and stressors (Smallbone et al. 2016), or even growth ( $\mathrm{Su}$ et al. 1996), as demonstrated in a range of species. The establishment of selection programmes based on the improvement of one biological trait (typically growth) must thus consider the impact on genetic diversity.

\section{5-How to optimise studies of fish domestication}

\section{5-1-Intrinsic factors influencing phenotypic responses to domestication}

Interpreting the effects of domestication is complex, because multiple intrinsic factors can influence fish phenotypes at the various steps of domestication and are naturally linked to the advancement of domestication. Species is the most obvious factor. This review found large interspecific differences in response to the trajectories and paths of domestication. FishBase 
has identified more than 34200 species of fish, representing a potential large reservoir for addressing questions of the effects of domestication. All of these species, however, are not potentially amenable to domestication, as suggested by a functional approach (Lecocq et al. 2019). A range of criteria should also be considered to identify the best candidates, such as their commercial interest, their cost of production relative to that generated from the captures by conventional fisheries, their flesh quality for human consumption, their capacity to be reared in captivity, and their advantages over species already farmed or domesticated. The number of relevant species for addressing the question of domestication effects is thus much more reduced. This may account for why broad comparisons of these effects between wild and domesticated fish are difficult to discern from the literature, because extensive bibliographical information is available for very few domesticated species, about 15 (Teletchea \& Fontaine 2014). The conceptualisation of the consequences of fish domestication thus requires choosing the best fish models to avoid confusion from the many interspecific peculiarities and thus to straightforwardly demonstrate the main biological guidelines driven by domestication. The choice of models may depend on factors at the phylogenetic level by selecting species from different families. Species could also be selected using aquacultural considerations based on a posteriori failures or successes throughout the history of fish domestication. Species exhibiting contrasting phenotypes during domestication (e.g. tilapia with decreased growth vs salmonids with increased growth) may be targets of studies of comparative biology.

Age and weight are other intrinsic factors that may be considered. Indeed, domestication generally influences growth, so comparing wild (F0) and domesticated fish with both the same age and weight is difficult (Table 4). Some intrinsic factors such as sex, weight, age, nutrition, and state of maturity are also determinants of immunological, reproductive, or growth functions (Duffy et al. 2003; Milla et al. 2009). For example, morphological features 
of a fish (e.g. growth and weight) influence its reproductive capacity (e.g. Marimuthu et al. 2009), so the modification of these factors in captive fish may bias the effects of domestication. Most studies do not accurately document the characteristics of these intrinsic factors, such as age, so evaluating their impact on the comparison of populations differentiated by their advancement during domestication is difficult. Only a few studies have determined if intrinsic factors interfere with the effects of domestication. A field experiment comparing brown trout from wild-born parents and from seventh-generation hatchery stock found that reproductive success was sex-dependent (Dannewitz et al. 2004).

The genetic background of populations is also relevant to the usual internal components potentially affecting the effects of domestication. A close relationship between reproductive failure and inbreeding has been identified in many captive fish. For example, genetic diversity was substantially reduced in one generation in a captive population of Senegalese sole that had problems spawning, demonstrating that the absence of genetic screening may lead to serious disturbances during domestication (Porta et al. 2006). Genetic diversity also often differs greatly between wild and domesticated populations (Ben Khadher et al. 2016). Together with the close relationships between heterozygosity and some biological traits linked to growth and reproduction (Lieutenant-Gosselin and Bernatchez 2006), we can assume that phenotypic differences between populations at different stages of domestication may remain unexplained due to the absence of clear information for the genetic features of the fish. The traceability of broodstock is notably not always managed properly in the early generations of uncontrolled artificial selection, because broodstocks are sometimes randomly chosen or are too small for adequate mating, and crosses amongst siblings may have negative consequences in future generations due to the effects of inbreeding. Scientific studies may even also suffer from a lack of genetic analysis that could rule out genetic alterations during domestication as the source of phenotypic differences. 
In addition to the lack of genetic information, defects of broodstock traceability can mask important information about the advancement of domestication. Domestication of a species or population, but even at the individual level, proceeds to a continuum starting from the capture of wild fish to the long-term adaptation to the captive system (Figure 1). Identifying the exact advancement of the animal or population along this continuum is therefore necessary. In particular, acclimation, which here refers to the period of allostatic load of a fish population after capture, must not be confounded with adaptation, defined as changes over several generations, to ensure that genes are passed on to the next generation (Flynn et al. 2014). Indeed, the mechanisms behind these processes differ greatly and can unfortunately notably superimpose when wild fish under acclimation are compared to fish that have spent generations in captivity.

Not all farms/studies have kept rigorous records of the number of generations in captivity, even for adapted fish, so the exact advancement of the captive fish during domestication is unknown, demonstrating why most studies do not specify the number of generations and features of mating (Table 4). In addition to this lack of traceability, the level of domestication is not homogenous amongst experiments, which causes further confusion for delineating the effects of domestication, as demonstrated for reproductive function.

\section{5-2-Extrinsic factors influencing phenotypic responses to domestication}

Extrinsic factors should also be taken into account for understanding responses to domestication. Environmental factors such as temperature, photoperiod, salinity, and water quality influence all biological functions, including reproduction, growth, immunity, and response to stress. Population factors (e.g. density, genetic origin, and sex ratios) should also be considered in the success or failure of the paths of domestication, because they also 
581 influence all aspects of fish biology. The consequences of domestication on the same 582 population may thus vary under different environmental conditions during domestication, notably if they are not compatible with the biological requirements of the species.

Even if most studies ensure that fish from different stages of domestication have always been reared under the same environmental conditions after the initial stages of life, we cannot exclude distinct conditions before or during an experiment. If these differential environmental conditions differed before the experiment, they are not the effects of domestication but are the effects of some events of the past that can later affect biological traits. For example, the exposure of embryos to early stressful situations can lead to further alteration of juvenile physiology (Cadiz et al. 2018). A comparison of populations with different histories before an experiment led to specific responses to experimental treatments of reproductive control (Khendek et al. 2018) but also of growth and behaviour (Jonsson and Jonsson 2014). Attention in all cases should be paid to the description of these life paths in order to determine if the effects of domestication are due to adaptation to rearing conditions or to previous life events.

\section{5-3-A multifactorial (and multitrait) approach for studying the effects of domestication}

The effects of domestication are the sum or the combined effects of many factors affecting fish traits at various levels. Marked genomic changes have been observed during the first generations of domestication, as described earlier (Christie et al. 2016). Also, the genetic changes are amongst the largest that may occur and alter the phenotypes of domesticated fish. Changes of traits during domestication in some mammals have been suspected to be due to epigenetic changes transmissible from one generation to the next. These traits encompass changes of morphological, physiological, and behavioural characteristics such as reduced cranial capacity and tooth size, partial depigmentation, decreased flight distance towards 
humans, advancement of sexual maturation, attenuation of the activity of the HPI axis, and alteration of neurotransmitter systems (Trut et al. 2009). All these phenotypic alterations may be driven by epigenetic modulation and/or genetic selection and would be due to mild deficits of neural-crest cells during embryonic development when migration defects are particularly important (Pörtl and Jung 2017). Interestingly, most of these major traits belonging to "domestication syndromes" in some mammals are those commonly altered during the domestication of fish (e.g. reduced brain length, precocious puberty, decrease in frightening behaviour, decrease in cortisolemia, modification of neurotransmitter level). Epimutations in developmental genes during early stages of domestication have also been identified in farmed European sea bass, some of which are associated with genes involved in developmental processes that are expressed in embryonic structures, including the neural crest (Anastasiadi and Piferrer 2019). Even if accepting some comparative parallels between piscine and mammalian models is still premature, we cannot dismiss the idea that epigenetic mechanisms could strongly affect phenotypes during fish domestication, as recently demonstrated in tilapia (Podgorniak et al. 2019). These first indications may account for why such contrasted procedures of domestication could lead to common physiological effects such as increased growth or reduction of stress or modulation of immunological gene expression. Concurrently studying the alteration of genomic, genetic, and epigenetic mechanisms during adaptation to captivity therefore seems logical for identifying the molecular processes behind this evolution and the causes of phenotypic changes. More generally, these intrinsic factors (gene expression and genetic and epigenetic features) interact with extrinsic factors linked to domestication (e.g. type of cages, temperature, and stressors) that increase the complexity of understanding the evolution of phenotypes by domestication ( $\mathrm{Li}$ and Leatherland 2013; Gavery and Roberts 2017; Nguyen et al. 2017). Future research should thus focus on understanding the 
interactions of the environment with the epigenome, genetic characteristics, and epigenetic marks that could affect phenotypic expression.

\section{5-4-A proposed experimental strategy for studying the effects of domestication}

We propose the following practical guidelines based on these theoretical considerations to explore the effects of domestication on fish phenotypes. First, we suggest sampling wild fish and then producing successive generations in captivity while rigorously recording fish traceability. We recommend monitoring the level of environmental and populational characteristics and maintaining them as stable as possible to avoid the effects of external disturbances. Fish with equivalent characteristics (e.g. age, sex, reproductive stage) and already acclimated to their environment should be sampled in each generation. Morphoanatomical and physiological analyses linked to the potential "vertebrate domestication syndrome" should be carried out on all generations, starting from wild fish sampled in their natural environment. These analyses would allow us to describe the phenotypic changes due to domestication. Omics technology (e.g. RNA-Seq or proteomics) or qPCR should be used to identify the molecular mechanisms within targeted organs (e.g. brain, head kidney, gonads) affected during domestication. An epigenetic analysis may be performed in parallel to link the changes in phenotype and gene expression with potential multigenerational epigenetic inheritance. Finally, a genetic analysis should be performed to estimate the putative loss of genetic variability in the generations of domestication. All data (anatomy, physiology, genetics, epigenetics, gene expression) should be gathered and examined using multifactorial statistical analysis to draw conclusions about the causes of phenotypic changes from generation to generation. These experiments must then be repeated in several species after the application of various domestication processes (range of trajectories and paths of 
655

656

657

658

659

660

661

662

663

664

665

666

667

668

669

670

domestication). These experiments should include farmed species but should also include fish biological models (e.g. zebrafish) that exhibit a range of assets (e.g. short biological cycle) and for which extensive molecular information is available. If a homogenous interspecific response is obtained, we could conclude that a domestication syndrome exists in fish, which could be a future guide for predicting the effects of domestication and evaluating the advancement of domestication for a given fish population.

\section{Conclusion}

Domestication is a strong regulator of biological functions in fish. A wide variety of biological processes can be affected in a wide range of fish species or families. In particular, domestication increases fish growth, attenuates stress responses, and regulates immunological genes. The influence on reproduction, however, is quite variable. Caution, however, should be exercised when considering the intrinsic and extrinsic factors associated with fish and all biological processes as potential sources of these changes when standardising investigations and more thoroughly describing the phenotypes of domesticated fish. 


\section{References}

De Almeida TR, Alix M, Cam A Le, Klopp C, Montfort J, Toomey L, Ledoré Y, Bobe J, Chardard D, Schaerlinger B, Fontaine P (2019) Domestication may affect the maternal mRNA profile in unfertilized eggs, potentially impacting the embryonic development of Eurasian perch (Perca fluviatilis). PLoS ONE. 14(12):e0226878.

Anastasiadi D, Piferrer F (2019) Epimutations in developmental genes underlie the onset of domestication in farmed European sea bass. Molecular Biology and Evolution 36: 22522264.

Araújo BC, Honji RM, de Mello PH, Moreira RG (2012) The influence of captive breeding on the fatty acid profiles of Salminus hilarii (Characiformes: Characidae) eggs and larvae. Aquaculture International 20: 1161-1181.

Awata S, Tsuruta T, Yada T, Iguchi K (2011) Effects of suspended sediment on cortisol levels in wild and cultured strains of ayu Plecoglossus altivelis. Aquaculture 314: 115-121.

Brummett RE, Angoni DE, Pouomogne V (2004) On-farm and on-station comparison of wild and domesticated Cameroonian populations of Oreochromis niloticus. Aquaculture 242: $157-164$.

Ben Khadher S, Fontaine P, Milla S, Agnèse JF, Teletchea F (2016) Genetic characterization and relatedness of wild and farmed Eurasian perch (Perca fluviatilis): Possible implications for aquaculture practices. Aquaculture Reports 3: 136-146.

Cadiz L, Ernande B, Quazuguel P, Servili A, Zambonino-Infante JL, Mazurais D (2018) Moderate hypoxia but not warming conditions at larval stage induces adverse carry-over effects on hypoxia tolerance of European sea bass (Dicentrarchus labrax) juveniles. Marine Environmental Research 138: 28-35.

Castanheira MF, Conceição LEC, Millot S, Rey S, Bégout ML, Damsgård B, Kristiansen T, 
Höglund E, Øverli Ø, Martins CIM (2017) Coping styles in farmed fish: consequences for aquaculture. Reviews in Aquaculture 9: 23-41.

Cerqueira M, Rey S, Silva T, Featherstone Z, Crumlish M, MacKenzie S (2016) Thermal preference predicts animal personality in Nile tilapia Oreochromis niloticus. The Journal of animal ecology 85: 1389-1400.

Chen X, Wang J, Qian L, Gaughan S, Xiang W, Ai T, Fan Z, Wang C (2017) Domestication drive the changes of immune and digestive system of Eurasian perch (Perca fluviatilis). PLOS ONE 12: e0172903.

Cho SJ, Caldwell C a., Gould WR (2009) Physiological Stress Responses of Rio Grande Silvery Minnow: Effects of Individual and Multiple Physical Stressors of Handling, Confinement, and Transport. North American Journal of Fisheries Management 29: $1698-1706$.

Christie MR, Marine ML, Fox SE, French RA, Blouin MS (2016) A single generation of domestication heritably alters the expression of hundreds of genes. Nature Communications 7: :10676.

Cieśla M, Jończyk R, Gozdowski D, Śliwiński J, Rechulicz J, Andrzejewski W (2014) Changes in ide Leuciscus idus (L.) females' reproductive parameters after stimulation with carp pituitary homogenate $(\mathrm{CPH})$ and Ovopel: The effect of domestication? Aquaculture International 22: 77-88.

Cleary JJ, Pankhurst NW, Battaglene SC (2000) The effect of capture and handling stress on plasma steroid levels and gonadal condition in wild and farmed snapper Pagrus auratus (Sparidae). Journal of the World Aquaculture Society 31: 558-569.

Crespel A, Rime H, Fraboulet E, Bobe J, Fauvel C (2008) Egg quality in domesticated and wild seabass (Dicentrarchus labrax): A proteomic analysis. Cybium, Revue Internationale d'Ichtyologie 32: 205. 
Dannewitz J, Petersson E, Dahl J, Prestegaard T, Löf AC, Järvi T (2004) Reproductive success of hatchery-produced and wild-born brown trout in an experimental stream. Journal of Applied Ecology 41: 355-364.

David P (1999) A quantitative model of the relationship between phenotypic variance and heterozygosity at marker loci under partial selling. Genetics 153: 1463-1474.

Debes P V., Normandeau E, Fraser DJ, Bernatchez L, Hutchings JA (2012) Differences in transcription levels among wild, domesticated, and hybrid Atlantic salmon (Salmo salar) from two environments. Molecular Ecology 21: 2574-2587.

Douxfils J, Deprez M, Mandiki SNM, Milla S, Henrotte E, Mathieu C, Silvestre F, Vandecan M, Rougeot C, Mélard C, Dieu M, Raes M, Kestemont P (2012) Physiological and proteomic responses to single and repeated hypoxia in juvenile Eurasian perch under domestication - Clues to physiological acclimation and humoral immune modulations. Fish and Shellfish Immunology 33: 1112-1122.

Douxfils J, Mandiki SNM, Marotte G, Wang N, Silvestre F, Milla S, Henrotte E, Vandecan M, Rougeot C, Mélard C, Kestemont P (2011) Does domestication process affect stress response in juvenile Eurasian perch Perca fluviatilis? Comparative Biochemistry and Physiology - A Molecular and Integrative Physiology 159: 92-99.

Douxfils J, Mathieu C, Mandiki SNM, Milla S, Henrotte E, Wang N, Vandecan M, Dieu M, Dauchot N, Pigneur LM, Li X, Rougeot C, Mélard C, Silvestre F, van Doninck K, Raes M, Kestemont P (2011) Physiological and proteomic evidences that domestication process differentially modulates the immune status of juvenile Eurasian perch (Perca fluviatilis) under chronic confinement stress. Fish and Shellfish Immunology 31: 11131121.

Duffy JE, Carlson EA, Li Y, Prophete C, Zelikoff JT (2003) Age-related differences in the sensitivity of the fish immune response to a coplanar PCB. Ecotoxicology 12: 251-259. 
Dupont-Nivet M, Vandeputte M, Haffray P, Chevassus B (2006) Effect of different mating designs on inbreeding, genetic variance and response to selection when applying individual selection in fish breeding programs. Aquaculture 252: 161-170.

Evenhuis JP, Leeds TD, Marancik DP, Lapatra SE, Wiens GD (2015) Rainbow trout (Oncorhynchus mykiss) resistance to columnaris disease is heritable and favorably correlated with bacterial cold water disease resistance. Journal of Animal Science 93: $1546-1554$.

Felip A, Zanuy S, Muriach B, Cerdá-Reverter JM, Carrillo M (2008) Reduction of sexual maturation in male Dicentrarchus labrax by continuous light both before and during gametogenesis. Aquaculture 275: 347-355.

Fleming IA, Agustsson T, Finstad B, Johnsson JI, Björnsson BT (2002) Effects of domestication on growth physiology and endocrinology of Atlantic salmon ( Salmo salar ). Canadian Journal of Fisheries and Aquatic Sciences 59: 1323-1330.

Fleming IA, Jonsson B, Gross MR, Lamberg A (1996) An Experimental Study of the Reproductive Behaviour and Success of Farmed and Wild Atlantic Salmon (Salmo salar). The Journal of Applied Ecology 33: 893-905.

Flynn KJ, St John M, Raven JA, Skibinski DOF, Allen JI, Mitra A, Hofmann EE (2014) HORIZONS: Acclimation, adaptation, traits and trade-offs in plankton functional type models: Reconciling terminology for biology and modelling. Journal of Plankton Research 37: 683-691.

Fontaine P, Legendre M, Vandeputte M, Fostier A (2009) Domestication de nouvelles espéces et développement durable de la pisciculture. Cahiers Agricultures 18: 119-124. Fontaine P, Teletchea F (2019) Domestication of the Eurasian Perch ( Perca fluviatilis ). 'Anim. Domest.' (Ed F Teletchea) doi:10.5772/intechopen.85132.

Fraslin C, Dechamp N, Bernard M, Krieg F, Hervet C, Guyomard R, Esquerré D, Barbieri J, 

Kuchly C, Duchaud E, Boudinot P, Rochat T, Bernardet JF, Quillet E (2018) Quantitative trait loci for resistance to Flavobacterium psychrophilum in rainbow trout: Effect of the mode of infection and evidence of epistatic interactions. Genetics Selection Evolution 50: 60.

Friars GW, Smith PJ (2010) Heritability, correlation and selection response estimates of some traits in fish populations. Atlantic Salmon Federation Technical Report.

Fuentes A, Fernández-Segovia I, Serra JA, Barat JM (2010) Comparison of wild and cultured sea bass (Dicentrarchus labrax) quality. Food Chemistry 119: 1514-1518.

Gavery MR, Roberts SB (2017) Epigenetic considerations in aquaculture. PeerJ 5: e4147.

Gjedrem T (2012) Genetic improvement for the development of efficient global aquaculture: A personal opinion review. Aquaculture 344-349: 12-22.

Glover KA, Otterå H, Olsen RE, Slinde E, Taranger GL, Skaala Ø (2009) A comparison of farmed, wild and hybrid Atlantic salmon (Salmo salar L.) reared under farming conditions. Aquaculture 286: 203-210.

Greenbaum D, Colangelo C, Williams K, Gerstein M (2003) Comparing protein abundance and mRNA expression levels on a genomic scale. Genome Biology 4: 117.

Grigorakis K (2007) Compositional and organoleptic quality of farmed and wild gilthead sea bream (Sparus aurata) and sea bass (Dicentrarchus labrax) and factors affecting it: A review. Aquaculture 272: 55-75.

Guzmán JM, Rubio M, Ortiz-Delgado JB, Klenke U, Kight K, Cross I, Sánchez-Ramos I, Riaza A, Rebordinos L, Sarasquete C, Zohar Y, Mañanós EL (2009) Comparative gene expression of gonadotropins (FSH and $\mathrm{LH}$ ) and peptide levels of gonadotropin-releasing hormones (GnRHs) in the pituitary of wild and cultured Senegalese sole (Solea senegalensis) broodstocks. Comparative Biochemistry and Physiology - A Molecular and Integrative Physiology 153: 266-277. 
Harvey AC, Skilbrei OT, Besnier F, Solberg MF, Sørvik AGE, Glover KA (2018) Implications for introgression: Has selection for fast growth altered the size threshold for precocious male maturation in domesticated Atlantic salmon? BMC Evolutionary Biology.

Hassin S, De Monbrison D, Hanin Y, Elizur A, Zohar Y, Popper DM (1997) Domestication of the white grouper, Epinephelus aeneus. 1. Growth and reproduction. Aquaculture 156: 305-316.

Hedenskog M, Petersson E, Järvi T (2002) Agonistic Behavior and Growth in Newly Emerged Brown Trout (Salmo trutta L) of Sea-Ranched and Wild Origin. Aggressive Behavior 28: 145-153.

Honji RM, Nóbrega RH, Pandolfi M, Shimizu A, Borella MI, Moreira RG (2013) Immunohistochemical study of pituitary cells in wild and captive Salminus hilarii (Characiformes: Characidae) females during the annual reproductive cycle. SpringerPlus 2: $1-14$.

Huntingford F, Jobling M, Kadri S (2012) ‘Aquaculture and Behavior.

Ibarra-Zatarain Z, Fatsini E, Rey S, Chereguini O, Martin I, Rasines I, Alcaraz C, Duncan N (2016) Characterization of stress coping style in Senegalese sole (Solea Senegalensis) juveniles and breeders for aquaculture. Royal Society Open Science 3: 160495.

Imanaga Y, Nyuji M, Amano M, Takahashi A, Kitano H, Yamaguchi A, Matsuyama M (2014) Characterization of gonadotropin-releasing hormone and gonadotropin in jack mackerel (Trachurus japonicus): Comparative gene expression analysis with respect to reproductive dysfunction in captive and wild fish. Aquaculture 428-429: 226-235.

Johnsson JI, Höjesjö J, Fleming IA (2001) Behavioural and heart rate responses to predation risk in wild and domesticated Atlantic salmon. Canadian Journal of Fisheries and Aquatic Sciences 58: 788-794. 
Johnston IA, Li X, Vieira VLA, Nickell D, Dingwall A, Alderson R, Campbell P, Bickerdike R (2006) Muscle and flesh quality traits in wild and farmed Atlantic salmon. Aquaculture 256: 323-336.

Jonsson B, Jonsson N (2014) Early environment influences later performance in fishes. Journal of Fish Biology 85: 151-188.

Kalbe M, Eizaguirre C, Dankert I, Reusch TBH, Sommerfeld RD, Wegner KM, Milinski M (2009) Lifetime reproductive success is maximized with optimal major histocompatibility complex diversity Lifetime reproductive success is maximized with optimal major histocompatibility complex diversity. Proceedings of the Royal Society Biological Sciences 276: 925-934.

Khendek A, Alix M, Viot S, Ledoré Y, Rousseau C, Mandiki R, Kestemont P, Policar T, Fontaine P, Milla S (2017) How does a domestication process modulate oogenesis and reproduction performance in Eurasian perch? Aquaculture 473: 206-214.

Khendek A, Chakraborty A, Roche J, Ledoré Y, Personne A, Policar T, Żarski D, Mandiki R, Kestemont P, Milla S, Fontaine P (2018) Rearing conditions and life history influence the progress of gametogenesis and reproduction performances in pikeperch males and females. Animal 12: 2335-2346.

Koolhaas JM, Korte SM, De Boer SF, Van Der Vegt BJ, Van Reenen CG, Hopster H, De Jong IC, Ruis MAW, Blokhuis HJ (1999) Coping styles in animals: Current status in behavior and stress- physiology. Neuroscience and Biobehavioral Reviews 23: 925-935.

Krejszeff S, Targońska K, Zarski D, Kucharczyk D (2009) Domestication affects spawning of the ide (Leuciscus idus)-preliminary study. Aquaculture 295: 145-147.

Krejszeff S, Targońska K, Zarski D, Kucharczyk D (2010) Artificial reproduction of two different spawn-forms of the chub. Reproductive Biology 10: 67-74.

Křišt’an J, Stejskal V, Policar T (2012) Comparison of reproduction characteristics and 

broodstock mortality in farmed and wild eurasian perch (Perca fluviatilis L.) females during spawning season under controlled conditions. Turkish Journal of Fisheries and Aquatic Sciences 12: 1.

Kujawa R, Kucharczyk D, Mamcarz A, Zarski D, Targońska K (2011) Artificial spawning of common tench Tinca tinca (Linnaeus, 1758), obtained from wild and domestic stocks. Aquaculture International 19: 513-521.

Lambert Y, Dutil J, Ouellet P (2000) Nutritional condition and reproductive success in wild fish populations. InNorberg B et al. (Ed. . (ed) 'Bergen (Norway)', Bergen. 499 pp. (Proceedings of the 6th International Symposium on the Reproductive Physiology of Fish: Bergen)

Lanes CFC, Bizuayehu TT, Bolla S, Martins C, de Oliveira Fernandes JM, Bianchini A, Kiron V, Babiak I (2012) Biochemical composition and performance of Atlantic cod (Gadus morhua L.) eggs and larvae obtained from farmed and wild broodstocks. Aquaculture 324-325: 267-275.

Langen K, Bakker TCM, Baldauf SA, Shrestha J, Thünken T (2017) Effects of ageing and inbreeding on the reproductive traits in a cichlid fish I: The male perspective. Biological Journal of the Linnean Society 120: 752-761.

Lecocq T, Benard A, Pasquet A, Nahon S, Ducret A, Dupont-Marin K, Lang I, Thomas M (2019) TOFF, a database of traits of fish to promote advances in fish aquaculture. Scientific data. 6: 301 .

Lenas D, Chatziantoniou S, Nathanailides C, Triantafillou D (2012) Comparison of wild and farmed sea bass (Dicentrarchus labrax L) lipid quality. Procedia Food Science 1: 11391146.

Lepage O, Øverli Ø, Petersson E, Järvi T, Winberg S (2000) Differential stress coping in wild and domesticated sea trout. Brain, Behavior and Evolution 56: 259-268. 
Li M, Leatherland JF (2013) The implications for aquaculture practice of epigenomic programming of components of the endocrine system of teleostean embryos: Lessons learned from mammalian studies. Fish and Fisheries 14: 528-553.

Lieutenant-Gosselin M, Bernatchez L (2006) Local heterozygoty-fitness correlations with global positive effects on fitness in threespeine stickleback. Evolution 282:20152230.

Longalong FM, Eknath AE (1995) Development of techniques for synchronization of natural spawning in Nile tilapia (Oreochromis niloticus). Aquaculture 137: 284-292.

Lorenzen K, Beveridge MCM, Mangel M (2012) Cultured fish: Integrative biology and management of domestication and interactions with wild fish. Biological Reviews 87:

Lucas MD, Drew RE, Wheeler PA, Verrell PA, Thorgaard GH (2004) Behavioral Differences among Rainbow Trout Clonal Lines. Behavior Genetics 34: 355-365.

Lund I, Steenfeldt SJ, Suhr KI, Hansen BW (2008) A comparison of fatty acid composition and quality aspects of eggs and larvae from cultured and wild broodstock of common sole (Solea solea L.). Aquaculture Nutrition 14: 544-555.

Mairesse G, Thomas M, Gardeur JN, Brun-Bellut J (2006) Effects of geographic source, rearing system, and season on the nutritional quality of wild and farmed Perca fluviatilis. Lipids 41: 221-229.

Mairesse G, Thomas M, Gardeur JN, Brun-Bellut J (2007) Effects of dietary factors, stocking biomass and domestication on the nutritional and technological quality of the Eurasian perch Perca fluviatilis. Aquaculture 262: 86-94.

Marimuthu K, Arumugam J, Sandragasan D, Jegathambigai R (2009) Studies on the fecundity of native fish climbing perch (Anabas testudineus, Bloch) in Malaysia. AmericanEurasian Journal of Sustainable Agriculture 3: 266-274.

Mazur CF, Iwama GK (1993) Effect of handling and stocking density on hematocrit, plasma cortisol, and survival in wild and hatchery-reared chinook salmon (Oncorhynchus 

tshawytscha). Aquaculture 112: 291-299.

897

898

899

900

901

902

903

904

905

906

907

908

909

910

911

912

913

914

915

916

917

918

919

920

Mignon-Grasteau S, Boissy A, Bouix J, Faure JM, Fisher AD, Hinch GN, Jensen P, Le Neindre P, Mormède P, Prunet P, Vandeputte M, Beaumont C (2005) Genetics of adaptation and domestication in livestock. Livestock Production Science 93: 3-14.

Milla S, Wang N, Mandiki SNM, Kestemont P (2009) Corticosteroids: Friends or foes of teleost fish reproduction? Comparative Biochemistry and Physiology - A Molecular and Integrative Physiology 153: 242-251.

Mohanty BR, Sahoo PK, Mahapatra KD, Saha JN (2012) Differential resistance to edwardsiellosis in rohu (Labeo rohita) families selected previously for higher growth and/or aeromoniasis-resistance. Journal of Applied Genetics 53: 107-114.

Moreira RG, Honji RM, Melo RG, de Moraes Narcizo A, Amaral JS, de Carvalho Araújo R, Hilsdorf AWS (2015) The involvement of gonadotropins and gonadal steroids in the ovulatory dysfunction of the potamodromous Salminus hilarii (Teleostei: Characidae) in captivity. Fish Physiology and Biochemistry 41: 1435-1447.

Neff BD, Garner SR, Fleming IA, Gross MR (2015) Reproductive success in wild and hatchery male coho salmon. Royal Society Open Science 2: 150161.

Nguyen NH, Hamzah A, Thoa NP (2017) Effects of genotype by environment interaction on genetic gain and genetic parameter estimates in Red tilapia (Oreochromis spp.). Frontiers in Genetics 8: 82.

Nikoo M, Falahatkar B (2012) Physiological Responses in Wild Broodstocks of the Caspian Kutum (Rutilus frisii kutum) Subjected to Transportation Stress. Journal of Applied Animal Welfare Science 15: 372-382.

O’Malley KG, Sakamoto T, Danzmann RG, Ferguson MM (2003) Quantitative trait loci for spawning date and body weight in rainbow trout: Testing for conserved effects across ancestrally duplicated chromosomes. Journal of Heredity 94: 273-284. 
Okpala COR, Sardo G, Vitale S (2017) On the acclimatization of pelagic fish species juveniles in a closed environment: An atlantic horse mackerel case study. American Journal of Animal and Veterinary Sciences 12: 65-70.

Osure GO, Phelps RP (2006) Evaluation of reproductive performance and early growth of four strains of Nile tilapia (Oreochromis niloticus, L) with different histories of domestication. Aquaculture 253: 485-494.

Øverli Ø, Pottinger TG, Carrick TR, Øverli E, Winberg S (2001) Brain monoaminergic activity in rainbow trout selected for high and low stress responsiveness. Brain, Behavior and Evolution 57: 214-224.

Palińska-Żarska K, Woźny M, Kamaszewski M, Szudrowicz H, Brzuzan P, Żarski D (2020) Domestication process modifies digestion ability in larvae of Eurasian perch (Perca fluviatilis), a freshwater Teleostei. Scientific Reports 10(1):6248.

Pasquet A (2019) Effects of Domestication on Fish Behaviour. 'Anim. Domest.'

Podgorniak T, Brockmann S, Konstantinidis I, Fernandes JMO (2019) Differences in the fast muscle methylome provide insight into sex-specific epigenetic regulation of growth in Nile tilapia during early stages of domestication. Epigenetics 14: 818-836.

Porta J, María Porta J, Martínez-Rodríguez G, del Carmen Alvarez M (2006) Development of a microsatellite multiplex PCR for Senegalese sole (Solea senegalensis) and its application to broodstock management. Aquaculture 256: 159-166.

Pörtl D, Jung C (2017) Is dog domestication due to epigenetic modulation in brain? Dog Behavior 2: 21-32.

Pottinger TG, Carrick TR (2000) Indicators of reproductive performance in rainbow trout Oncorhynchus mykiss (Walbaum) selected for high and low responsiveness to stress. Aquaculture Research 31: 367-375.

Pottinger TG, Pickering AD, Hurley MA (1992) Consistency in the stress response of 
individuals of two strains of rainbow trout, Oncorhynchus mykiss. Aquaculture 103: $275-289$.

948

949

950

951

952

953

954

955

956

957

958

959

960

961

962

963

964

965

966

967

968

969

970

Priars GW, Smith P (2010) Heritability, correlation and selection response estimates of some traits in fish populations. (Tech rep, Huntsman Marine Science Centre)

Price EO (1999) Behavioral development in animals undergoing domestication. Applied Animal Behaviour Science 65: 245-271.

Randak T, Kocour M, Zlabek V, Policar T, Jarkovsky J (2006) Effect of culture conditions on reproductive traits of brown trout Salmo trutta L. Bulletin Francais De La Peche Et De La Pisciculture 383, 1-12.

Raoult V, Brown C, Zuberi A, Williamson JE (2012) Blood cortisol concentrations predict boldness in juvenile mulloway (Argyosomus japonicus). Journal of Ethology 30: 225232.

Reinhardt UG, Yamamoto T, Nakano S (2001) Effects of body size and predators on intracohort competition in wild and domesticated juvenile salmon in a stream. Ecological Research 16: 327-334.

Robison BD, Rowland W (2005) A potential model system for studying the genetics of domestication: behavioral variation among wild and domesticated strains of zebra danio ( Danio rerio ). Canadian Journal of Fisheries and Aquatic Sciences 62: 2046-2054.

Ruzzante DE, Doyle RW (1991) Rapid behavioral changes in medaka (Oryzias latipes) caused by selection for competitive and noncompetitive growth. Evolution 45: 1936.

Ruzzante DE, Doyle RW (1993) Evolution of Social-Behavior in a Resource-Rich, Structured Environment - Selection Experiments with Medaka (Oryzias-Latipes). Evolution 47:

Salze G, Tocher DR, Roy WJ, Robertson DA (2005) Egg quality determinants in cod (Gadus morhua L.): Egg performance and lipids in eggs from farmed and wild broodstock. Aquaculture Research 36: 1488-1499. 
Sampaio FDF, Freire CA (2016) An overview of stress physiology of fish transport: changes in water quality as a function of transport duration. Fish and Fisheries 17: 1055-1072.

Samy Yehya El-Zaeem (2012) Flesh quality differentiation of wild and cultured Nile tilapia (Oreochromis niloticus) populations. African journal of biotechnology 11: 4086-4089.

Sánchez P, Viñas J, Alvarado Bremer JR, Ambrosio PP, Flos R (2012) Loss of genetic variability in a hatchery strain of Senegalese sole (Solea senegalensis) revealed by sequence data of the mitochondrial DNA control region and microsatellite markers. Scientia Marina 76: 225-235.

Schreck CB, Contreras-Sanchez W, Fitzpatrick MS (2001) Effects of stress on fish reproduction, gamete quality, and progeny. Aquaculture 197: 3-24.

Segner H, Sundh H, Buchmann K, Douxfils J, Sundell KS, Mathieu C, Ruane N, Jutfelt F, Toften H, Vaughan L (2012) Health of farmed fish: Its relation to fish welfare and its utility as welfare indicator. Fish Physiology and Biochemistry 38: 85-105.

Silva RMO, Evenhuis JP, Vallejo RL, Tsuruta S, Wiens GD, Martin KE, Parsons JE, Palti Y, Lourenco DAL, Leeds TD (2019) Variance and covariance estimates for resistance to bacterial cold water disease and columnaris disease in two rainbow trout breeding populations. Journal of Animal Science 97: 1124-1132.

Silva PIM, Martins CIM, Engrola S, Marino G, Øverli Ø, Conceição LEC (2010) Individual differences in cortisol levels and behaviour of Senegalese sole (Solea senegalensis) juveniles: Evidence for coping styles. Applied Animal Behaviour Science 124: 75-81.

Smallbone W, van Oosterhout C, Cable J (2016) The effects of inbreeding on disease susceptibility: Gyrodactylus turnbulli infection of guppies, Poecilia reticulata. Experimental Parasitology 167: 32-37.

Sneddon LU, Braithwaite VA, Gentle MJ (2003) Do fishes have nociceptors? Evidence for the evolution of a vertebrate sensory system. Proceedings of the Royal Society B: 
997

998

999

1000

1001

1002

1003

1004

1005

1006

1007

1008

1009

1010

1011

1012

1013

1014

1015

1016

1017

1018

1019

1020

Solberg MF, Skaala Ø, Nilsen F, Glover KA (2013) Does Domestication Cause Changes in Growth Reaction Norms? A Study of Farmed, Wild and Hybrid Atlantic Salmon Families Exposed to Environmental Stress. PLoS ONE 8: e54469.

Sorbera L, Asturiano JF, Carrillo M, Zanuy S (2001) Effects of polyunsaturated fatty acids and prostaglandins on oocyte maturation in a marine teleost, the European sea bass (Dicentrarchus labrax). Biology of reproduction 64: 382-389.

Srisapoome P, Chatchaiphan S, Bunnoy A, Koonawootrittriron S, Na-Nakorn U (2019) Heritability of immunity traits and disease resistance of bighead catfish, Clarias macrocephalus Günther, 1864. Fish and Shellfish Immunology 92: 209-215.

Su GS, Liljedahl LE, Gall GAE (1996) Effects of inbreeding on growth and reproductive traits in rainbow trout (Oncorhynchus mykiss). Aquaculture 142: 139-148.

Swain DP, Riddell BE (1990) Variation in agonistic behavior between newly emerged juveniles from hatchery and wild populations of coho salmon, Oncorhynchus kisutch. Can J Fish Aquat Sci 47: 566-571.

Taranger GL, Carrillo M, Schulz RW, Fontaine P, Zanuy S, Felip A, Weltzien FA, Dufour S, Karlsen Ø, Norberg B, Andersson E, Hansen T (2010) Control of puberty in farmed fish. General and Comparative Endocrinology 165: 483-515.

Targońska K, Kucharczyk D, Żarski D, Cejko B, Krejszeff S, Kupren K, Król R, Dryl K, Kowalski R, Glogowski J (2011) Artificial reproduction of wild and cultured barbel ( Barbus barbus, Cyprinidae) under controlled conditions. Acta Veterinaria Hungarica 59: $363-372$.

Teletchea F, Fontaine P (2014) Levels of domestication in fish: Implications for the sustainable future of aquaculture. Fish and Fisheries 15: 181-195.

Tentelier C, Lepais O, Larranaga N, Manicki A, Lange F, Rives J (2016) Sexual selection 

leads to a tenfold difference in reproductive success of alternative reproductive tactics in male atlantic salmon. Science of Nature 103: 47.

Thoa NP, Hamzah A, Nguyen NH (2017) Genetic variation and correlated changes in reproductive performance of a red tilapia line selected for improved growth over three generations. Animal Reproduction Science 184: 94-101.

Thodesen J, Grisdale-Helland B, Helland SJ, Gjerde B (1999) Feed intake, growth and feed utilization of offspring from wild and selected Atlantic salmon (Salmo salar). Aquaculture 180: 237-246.

Trong TQ, Van Arendonk JAM, Komen H (2013a) Genetic parameters for reproductive traits in female Nile tilapia (Oreochromis niloticus): II. Fecundity and fertility. Aquaculture 416-417: 72-77.

Trong TQ, Van Arendonk JAM, Komen H (2013b) Genetic parameters for reproductive traits in female Nile tilapia (Oreochromis niloticus): I. Spawning success and time to spawn. Aquaculture 416-417: 57-64.

Trut L, Oskina I, Kharlamova A (2009) Animal evolution during domestication: The domesticated fox as a model. BioEssays 31, 349-360.

Tymchuk WE, Beckman B, Devlin RH (2009) Altered expression of growth hormone/insulinlike growth factor i axis hormones in domesticated fish. Endocrinology 150: 1809-1816.

Tymchuk WE, Biagi C, Withler R, Devlin RH (2006) Growth and Behavioral Consequences of Introgression of a Domesticated Aquaculture Genotype into a Native Strain of Coho Salmon. Transactions of the American Fisheries Society 135: 442-455.

Tymchuk WE, Devlin RH (2005) Growth differences among first and second generation hybrids of domesticated and wild rainbow trout (Oncorhynchus mykiss). Aquaculture 245: $295-300$.

Vandeputte M, Dupont-nivet M, Haffray P, Cenadelli S, Parati K, Vidal M, Vergnet A, 
Chatain B (2009) Response to domestication and selection for growth in the European sea bass (Dicentrarchus labrax). Aquaculture 286: 20-27.

Vaz-Serrano J, Ruiz-Gomez ML, Gjøen HM, Skov P V., Huntingford FA, Øverli, Höglund E (2011) Consistent boldness behaviour in early emerging fry of domesticated Atlantic salmon (Salmo salar): Decoupling of behavioural and physiological traits of the proactive stress coping style. Physiology and Behavior 103: 359-364.

Verbeek P, Iwamoto T, Murakami N (2008) Variable stress-responsiveness in wild type and domesticated fighting fish. Physiology and Behavior 93: 83-88.

Vindas MA, Gorissen M, Höglund E, Flik G, Tronci V, Damsgård B, Thörnqvist PO, Nilsen TO, Winberg S, Øverli Ø, Ebbesson LOE (2017) How do individuals cope with stress? Behavioural, physiological and neuronal differences between proactive and reactive coping styles in fish. Journal of Experimental Biology 220: 1524-1532.

Volckaert FAM, Hellemans B, Batargias C, Louro B, Massault C, Van Houdt JKJ, Haley C, De Koning DJ, Canario AVM (2012) Heritability of cortisol response to confinement stress in European sea bass dicentrarchus labrax. Genetics Selection Evolution 44: 15.

Wang N, Teletchea F, Kestemont P, Milla S, Fontaine P (2010) Photothermal control of the reproductive cycle in temperate fishes. Reviews in Aquaculture 2: 209-222.

Wedemeyer GA, Wydoski RS (2008) Physiological Response of Some Economically Important Freshwater Salmonids to Catch-and-Release Fishing. North American Journal of Fisheries Management 28: 1587-1596.

Wellenreuther M, Le Luyer J, Cook D, Ritchie PA, Bernatchez L (2019) Domestication and Temperature Modulate Gene Expression Signatures and Growth in the Australasian Snapper Chrysophrys auratus. Genes/Genome/Genetics 9: 105-116.

Wilkins AS, Wrangham RW, Tecumseh Fitch W (2014) The 'domestication syndrome' in mammals: A unified explanation based on neural crest cell behavior and genetics. 
Wittkopp PJ, Kalay G (2011) Cis-regulatory elements: molecular mechanisms and evolutionary processes underlying divergence. Nature Reviews Genetics 13: 59-69.

1074

Woodward CC, Strange RJ (2004) Physiological Stress Responses in Wild and HatcheryReared Rainbow Trout. Transactions of the American Fisheries Society 116: 574-579.

Wright D, Nakamichi R, Krause J, Butlin RK (2006) QTL analysis of behavioral and morphological differentiation between wild and laboratory zebrafish (Danio rerio). Behavior Genetics 36: 271-284.

Yue S, Moccia RD, Duncan IJH (2004) Investigating fear in domestic rainbow trout, Oncorhynchus mykiss, using an avoidance learning task. Applied Animal Behaviour Science 87: 343-354.

Zuberi A, Brown C, Ali S (2014) Effect of confinement on water-borne and whole body cortisol in wild and captive-reared rainbowfish (Melanoteania duboulayi). International Journal of Agriculture and Biology 16: 183-188.

Zupa R, Fauvel C, Mylonas CC, Santamaria N, Valentini L, Pousis C, Papadaki M, Suquet M, De la Gándara F, Bello G, De Metrio G, Corriero A (2013) Comparative analysis of male germ cell proliferation and apoptosis in wild and captive Atlantic bluefin tuna (Thunnus thynnus L.). Journal of Applied Ichthyology 29: 71-81.

Zupa R, Rodrõâguez C, Mylonas CC, Rosenfeld H, Fakriadis I, Papadaki M, Peârez JA, Pousis C, Basilone G, Corriero A (2017) Comparative study of reproductive development in wild and captive-reared greater amberjack seriola dumerili (Risso, 1810). PLOS ONE 12: e0169645. 


\begin{tabular}{|c|c|c|c|}
\hline Species & Comparison & Effect of domestication & Reference \\
\hline \multicolumn{4}{|l|}{ Negative effects on growth: } \\
\hline Oreochromis niloticus & F0 vs domesticated & Decrease of growth rate in ponds & (Brummett et al. 2004) \\
\hline \multicolumn{4}{|l|}{ Positive effects on growth: } \\
\hline Salmo salar & F1 vs F7 & Increase in weight, length, and condition factor after selection for growth, fillet quality, and late maturation & (Glover et al. 2009) \\
\hline Salmo salar & F1 vs F10 & Increase in weight and length after selection for growth, fillet quality, and late maturation & (Solberg et al. 2013) \\
\hline Salmo salar & F1 vs F5 & Increase in weight and condition factor after selection for growth rate & (Thodesen et al. 1999) \\
\hline Salmo salar & F1 vs F5 & Increase in weight, plasma GH content, and pituitary GH content after selection for growth & (Fleming et al. 2002) \\
\hline Salmo trutta & F0 vs F6 & Increase in growth rate at low fish densities after selection for growth & (Hedenskog et al. 2002) \\
\hline Oncorhynchus mykiss & F1 vs domesticated & Increase in growth and length after controlled selection for growth & (Tymchuk and Devlin 2005) \\
\hline $\begin{array}{l}\text { Oncorhynchus mykiss and } \\
\text { Oncorhynchus kisutch }\end{array}$ & F1 vs domesticated & Increase in growth and length after controlled selection for growth & (Tymchuk et al. 2009) \\
\hline Dicentrarchus labrax & F1 vs F2 & No difference in growth & (Vandeputte et al. 2009) \\
\hline Perca fluviatilis & F0 vs F6 & Increase in weight, length and growth rate in larvae & (Palińska-Żarska et al. 2020) \\
\hline Perca fluviatilis & F0 vs F4 & Increase in weight and growth rate & (Douxfils, Mandiki, et al. 2011) \\
\hline Sander lucioperca & $\begin{array}{llll}\text { F0 vs F0 (reared in } \\
\text { RAS) }\end{array}$ & Increase in growth rate & (Khendek et al. 2018) \\
\hline Chrysophrys auratus & F0 vs F1 & Increase in weight, length and growth rate at high temperature & (Wellenreuther et al. 2019) \\
\hline
\end{tabular}

1095

1096

1097

1098

1099

1100

1101

1102

1103

1104

1105 
Table 2: Main domestication effects on reproductive features reported in teleost fish species

Species Comparison
Effect of domestication
Reference 


\begin{tabular}{|c|c|c|c|}
\hline \multicolumn{4}{|c|}{ Negative effects on reproductive capacity: } \\
\hline Oreochromis niloticus & F0 vs domesticated & Lower rates of ovulation and survival & (Osure and Phelps 2006) \\
\hline Seriola dumerili & Wild F0 vs captive F0 & $\begin{array}{l}\text { Lower levels of GSI and sex steroids (T, E2) for both sexes, high levels of oocyte atresia and failed ovulation, blockage of } \\
\text { spermatogenesis }\end{array}$ & (Zupa et al. 2017) \\
\hline Salminus hilarii & F0 vs domesticated & Disruption of final oocyte meiotic maturation, ovulation blockage, decreases in FSH and LH gene expression & (Moreira et al. 2015) \\
\hline Trachurus japonicus & Wild F0 vs captive F0 & $\begin{array}{l}\text { Lower GnRH1, FSH and LH gene expression and E2 levels, lower rates of gonadogenesis and oogenesis, ovulation } \\
\text { blockage }\end{array}$ & (Imanaga et al. 2014) \\
\hline Thunnus thynnus & Wild F0 vs captive F0 & Delay in germinal-cell proliferation, increased apoptosis in testis, reduction of spermatozoan mobility & (Zupa et al. 2013) \\
\hline Salminus hilarii & F1 vs domesticated & Lower rate of fertilisation, modification of oocyte lipid content & (Araújo et al. 2012) \\
\hline Salminus hilarii & Wild F0 vs captive F0 & Disruption of final oocyte maturation, blockage of spontaneous ovulation & (Honji et al. 2013) \\
\hline Perca fluviatilis & F0 vs domesticated & Lower rates of ovulation and hatching & (Křriš’an et al. 2012) \\
\hline Perca fluviatilis & F1 vs domesticated & Lower egg and larval quality (egg survival, hatching rate, malformation rates) & (Khendek et al. 2017) \\
\hline Sander lucioperca & F0 vs domesticated & Lower levels of GSI and sex hormones in females, slower oogenesis & (Khendek et al. 2018) \\
\hline Gadus morhua & F0 vs domesticated & Lower rates of fertilisation and hatching, decreased larval resistance to high salinity & (Lanes et al. 2012) \\
\hline Gadus morhua & F0 vs domesticated & Lower rates of fertilisation, hatching, and embryo survival & (Salze et al. 2005) \\
\hline Dicentrarchus labrax & F0 vs F3 & Lower rates of fertilisation and hatching, modification of lipid content in ova & (Crespel et al. 2008) \\
\hline Tinca tinca & F0 vs domesticated & Lower ovulation rate and sperm motility & (Kujawa et al. 2011) \\
\hline Leuciscus cephalus & F0 vs F2 & Lower ovulation rate, oocyte weight, and larval size at hatching & (Krejszeff et al. 2010) \\
\hline Leuciscus idus & F0 vs F4 & Lower embryo survival in response to Ovopel treatment & (Krejszeff et al. 2009) \\
\hline Leuciscus idus & F0 vs F1 vs F3 & $\begin{array}{l}\text { Lower ovulation rate after CPH treatment, positive correlation between level of domestication and latency time after } \\
\text { treatment }\end{array}$ & (Cieśla et al. 2014) \\
\hline Solea senegalensis & F0 vs F1 & Absence of spontaneous ovulation and no fertilisation if spontaneous ovulation & (Guzmán et al. 2009) \\
\hline Solea solea & F0 vs F2 & Lower rates of fertilisation, hatching, and survival & (Lund et al. 2008) \\
\hline Salmo salar & F0 vs F5 & Lower ovulation rate and embryo survival & (Fleming et al. 1996) \\
\hline \multicolumn{4}{|c|}{ Positive effects on reproductive capacity: } \\
\hline Salmo trutta & F0 vs F7 & Increase in sperm quality but no effect on females (wild environment) & (Dannewitz et al. 2004) \\
\hline Leuciscus cephalus & F0 vs F2 & Increase in annual spawn number & (Krejszeff et al. 2010) \\
\hline Leuciscus idus & F0 vs F4 & Increase in ovulation rate in response to Ovopel treatment & (Krejszeff et al. 2009) \\
\hline Barbus barbus & F0 vs domesticated & Increase in rates of ovulation and embryo survival in response to Ovaprim treatment & (Targońska et al. 2011) \\
\hline Perca fluviatilis & F0 vs domesticated & Increase in fertilisation rate, improvement of female survival rates after ovulation & (Křišt'an et al. 2012) \\
\hline Perca fluviatilis & F1 vs domesticated & Increase in levels of expression of GSI, GnRH, and gonadotropin genes during oogenesis & (Khendek et al. 2017) \\
\hline
\end{tabular}

\section{Table 3: Main domestication effects on stress reported in teleost fish species}




\begin{tabular}{|c|c|c|c|}
\hline Species & Comparison & Effect of domestication & Reference \\
\hline \multicolumn{4}{|c|}{ Positive effects on the stress response: } \\
\hline Plecoglossus altivelis & F0 vs F4 vs F39 & Lower serum cortisol concentrations in fish exposed for $3 \mathrm{~h}$ to water with $200 \mathrm{mg} / \mathrm{l} \mathrm{kaolin}$ & (Awata et al. 2011) \\
\hline Perca fluviatilis & F1 vs F4 & Lower plasma cortisol in fish exposed to confinement and $15 \mathrm{~min}$ in anaesthetic bath & (Douxfils, Mandiki, et al. 2011) \\
\hline Perca fluviatilis & F1 vs F5 & Lower splenosomatic index in fish exposed to repeated hypoxia & (Douxfils et al. 2012) \\
\hline Oncorhynchus mykiss & F0 vs domesticated & Lower levels of plasma glucose, brain DOPAC/DA, and brain 5-HIAA/5-HT & (Lepage et al. 2000) \\
\hline Melanoteania duboulayi & F0 vs F15 & Lower increase in cortisol content in fish confined in beaker for $30 \mathrm{~min}$ & (Zuberi et al. 2014) \\
\hline Oncorhynchus tshawytscha & F0 vs F1 & Lower increase in cortisol and haematocrit in fish exposed to density stressor & (Mazur and Iwama 1993) \\
\hline Betta splendens & F0 vs domesticated & No elevation in release of water-borne cortisol in fish exposed to unfamiliar environment and spatial confinement & (Verbeek et al. 2008) \\
\hline Oncorhynchus mykiss & F0 vs domesticated & $\begin{array}{l}\text { Lower increase in plasma cortisol and glucose and lower decrease in plasma chloride in fish exposed to confinement in a } \\
\text { net and to electroshock }\end{array}$ & (Woodward and Strange 2004) \\
\hline
\end{tabular}

1117

1118

1119

1120

1121

1122

1123

1124

1125

1126 Table 4: Some features of reproductive comparisons between wild and captive fish

1127

1128

1129

1130 
1131

\begin{tabular}{|c|c|c|c|c|c|c|c|}
\hline Species & Sex & Age & Weight & Comparison & Conditions of culture & Feeding & Reference \\
\hline Seriola dumerili & Males and females & - & $13-15 \mathrm{~kg}$ & Wild F0 vs captive F0 & Sea cage & Prey fish and commercial diets & (Zupa et al. 2017) \\
\hline Salminus hilarii & Females & - & $\begin{array}{l}843 \text { (wild) vs } \\
534 \mathrm{~g} \text { (captive) }\end{array}$ & $\begin{array}{l}\text { Wild F0 vs captive } \\
\text { (ponds) }\end{array}$ & River (F0) vs pond & Commercial diet (captive fish) & (Moreira et al. 2015) \\
\hline $\begin{array}{l}\text { Trachurus } \\
\text { japonicus }\end{array}$ & Males and females & - & $\begin{array}{l}307 \text { (wild) vs } \\
250 \text { (captive) }\end{array}$ & Wild F0 vs captive F0 & River (F0) vs cage (captive) & - & (Imanaga et al. 2014) \\
\hline Thunnus thynnus & Males & - & $\begin{array}{l}\text { ? (wild) vs 40- } \\
70 \text { kg (captive) }\end{array}$ & Wild F0 vs captiveF0 & Sea (F0) vs cage (captive) & - & (Zupa et al. 2013) \\
\hline Leuciscus idus & Males and females & $5-8$ years & $639-780 \mathrm{~g}$ & Wild F0 vs F1 vs F3 & Wild vs semi-pond culture & - & (Cieśla et al. 2014) \\
\hline Salminus hilarii & Females & - & $570 \mathrm{~g}$ & Wild F0 vs captive F0 & Ponds & Commercial diet & (Honji et al. 2013) \\
\hline Perca fluviatilis & Females & 3 years & $\begin{array}{l}146 \mathrm{~g} \text { (captive) } \\
\text { vs } 75 \mathrm{~g} \text { (wild) }\end{array}$ & F0 vs domesticated & $\begin{array}{llll}\begin{array}{l}\text { Pond-reared } \\
\text { (captive) }\end{array} & \text { (F0) } & \text { vs } & \text { RAS } \\
\end{array}$ & $\begin{array}{l}\text { Commercial diet and forage fish (captive) } \\
\text { vs forage fish (wild) }\end{array}$ & (Křišt’an et al. 2012) \\
\hline Salminus hilarii & Females & 3 years (dom.) & - & F1 vs domesticated & RAS & Commercial diet & (Araújo et al. 2012) \\
\hline Gadus morhua & Males and Females & 3 years (dom.) & $2,7-2,9 \mathrm{~kg}$ & F0 vs domesticated & RAS & Unfed & (Lanes et al. 2012) \\
\hline Tinca tinca & Males and Females & - & $0.3-1.4 \mathrm{~kg}$ & F0 vs domesticated & Lake (F0) vs pond (captive) & Unfed & (Kujawa et al. 2011) \\
\hline
\end{tabular}

1132

1133

1134

1135

1136

1137 
$1138 \quad$ Figure legend

1139

1140 Fig. 1. Schematic representation of the main steps of the fish domestication processes that can 1141 alter the fish phenotypes. The dotted line in step 5 indicates that this step can start either 1142 synchronously or after step 4.

1143 